\title{
Percutaneous Radiofrequency Ablation of Hepatocellular Carcinoma against the Diaphragm: Is Artificial Ascites Necessary?
}

\author{
Kathleen Khong, Ho Nguyen, Chin-Shang Li, Danny Cheng, John P. McGahan \\ Department of Radiology, University of California Davis, Sacramento, USA \\ Email: kathleen.khong@ucdmc.ucdavis.edu
}

Received 25 November 2013; revised 25 December 2013; accepted 7 January 2014

Copyright (C) 2014 by authors and Scientific Research Publishing Inc.

This work is licensed under the Creative Commons Attribution International License (CC BY). http://creativecommons.org/licenses/by/4.0/ (c) (i) Open Access

\begin{abstract}
Purpose: To evaluate the utility of artificial ascites induction for radiofrequency ablation (RFA) of peridiaphragmatic hepatocellular carcinoma (HCC) through retrospective cohort analysis comparing characteristics and complications of peridiaphragmatic HCC without the use of artificial ascites to non-peridiaphragmatic HCC. Materials and Methods: IRB approval was obtained. From September 2003 to December 2008, 150 consecutive patients with hepatic tumors received percutaneous RFA. 110 patients had presumed HCC, and of those 21 had lesions abutting the diaphragm. Of the remaining 89 patients with non-peridiaphragmatic HCC lesions, 21 were randomly selected for the comparison group. RFA volume, major and minor complication rates, pain, technical success, and recurrence rates were compared between the two groups. Results: There was no statistical difference in RFA volume $(P=0.962)$, overall major complication rate $(P=0.343)$ and minor complication rate $(P=0.118)$ between the two groups. However, the peridiaphragmatic group that underwent RFA with a clustered-needle demonstrated a statistically significant higher proportion of major complications compared to the non-peridiaphragmatic clustered-needle group $(P=0.033)$. There was no statistical difference in pain severity $(P=0.8802)$ or pain location $(P=0.15)$. There was no statistical difference in technical success rates $(P=1)$, local tumor progression rates $(P=1)$, or time to local tumor recurrence $(P=0.67)$. Conclusion: Artificial ascites induction for RFA of HCC lesions adjacent to the diaphragm may not be necessary, although clustered electrode technique should be avoided in this location as they present with a higher complication rate.
\end{abstract}

\section{Keywords}

Radiofrequency Ablation; Hepatocellular Carcinoma; Hepatoma; Artificial Ascites; Diaphragm 


\section{Introduction}

Radiofrequency ablation (RFA) has proven to be a safe and successful technique for the control and treatment of hepatic tumors [1]-[6]. However, complications can occur [4], [7]-[22]. Diaphragmatic injury during RFA of tumors adjacent to the diaphragm is one of the more commonly discussed complications with both animal and human studies addressing the frequency of injury after RFA [4], [9]-[25].

Reasons include difficulty of diaphragmatic visualization on ultrasound from overlapping ribs or adjacent lung, with the resultant high risk of thermal injury to the adjacent diaphragm [14], [26]-[30], or even the adjacent lung with resultant pleural effusions. The most concerning injury for the patient is local or referred shoulder pain from injury to the phrenic nerve.

Some have concluded that RFA adjacent to the diaphragm is contraindicated or that special interventional techniques are necessary to separate the diaphragm from the liver [23]-[25], which include artificial ascites, or hydrodissection [27], through improved visualization of tumor and reduced risk of diaphragmatic thermal injury [24], [27], [31]-[35].

However, the induction of artificial ascites prior to ablation can have possible potential drawbacks such as increased procedure time, incomplete success rate in patients with postoperative adhesions, and risk for bleeding, peritonitis, seeding, and increased rates of local tumor progression [31]-[38]. Given these potential drawbacks, we raise the question of its true utility. To our knowledge, there has been only one study by Kang [26] showing a slight increase of minor complications, and statistically significant increase in right shoulder pain in diaphragmatic lesions treated with RFA without artificial ascites.

We thus compare local complications and technical success of RFA of liver lesions abutting the diaphragm with lesions in non-subdiaphragmatic locations. Given diaphragm innervation anatomy with intercostal nerve supply of the peripheral portions and phrenic nerve supply more centrally, we also further evaluate pain based on diaphragmatic sublocations.

\section{Materials and Methods}

Approval was obtained from our Institutional Review Board. No written informed consent was required for this single-center retrospective cohort study. Between September 2003 and December 2008, percutaneous radiofrequency ablation using multiple or single internal cooled electrodes; or a cluster electrodes (Covidien, Boulder, CO) was performed on 150 consecutive patients with hepatic tumors. Inclusion criteria for the study included; a single hepatic tumor size $<4 \mathrm{~cm}$, or up to 3 hepatic tumors of size $<3 \mathrm{~cm}$, and absence of portal vein thrombosis, INR of less than 1.35, and a platelet count of greater than 50,000.

All ablations were performed in a standard fashion, using ultrasound (Acuson Sequoa, Siemens Healthcare) with a 4-MHz sector transducer for electrode placement and then utilizing noncontrast CT (16-MDCT LightSpeed CT, GE Healthcare or 64-MDCT Somatom Definition Dual Source, Siemens Healthcare) to document electrode position and relationship to surrounding structures. When there was a liver hepatoma abutting the diaphragm, defined as a lesion with any portion of the margin in contact with the diaphragm by imaging, the electrode was placed $5 \mathrm{~mm}$ proximal to the diaphragm initially using sonographic guidance (Figure 1) and additionally using CT confirmation of placement. In nonperidiaphragmatic tumors, the electrode was placed within the lesion centrally, using sonographic guidance.

All ablations were performed by one faculty member with over 10 years experience in RFA, and using one radiofrequency generator (Radionics, Covidien) to minimize variables. Needle electrodes were all saline-perfused cooled-tip internally cooled single or clustered electrodes (Cool-Tip RF Ablation Electrodes, Covidien.)

RFA was performed using a gradual ramp of power with a starting power of $30 \mathrm{~W}$ which was gradually increased by $10 \mathrm{~W}$ each minute using the impedance control mode, and stopping when three separate "roll offs" of power occurred [39]. No hydrodissection was used in any cases. There was no difference in ablation settings or parameters for peridiaphragmatic compared to nonperidiaphragmatic tumors.

Assessment of therapeutic success was determined by four-phase liver computed tomography obtained within 24-hour after completion of the procedure. Diagnostic CTs were performed with either a General Electric (16-Dectector) light speed CT (General Electric, Milwaukee, WI) or Siemens Somatom Definition Dual Source (64-Detector) CT (Siemens Medical Solutions USA, Malvern, PA). This included a four-phase liver CT with a base scan, an arterial phase (delay of approximately 25 - 30 seconds), portal phase (delay of approximately 70 80 seconds), and equilibrium phase (delay of approximately 180 seconds). A volume of $125 \mathrm{ml}$ of Iohexol (Om- 


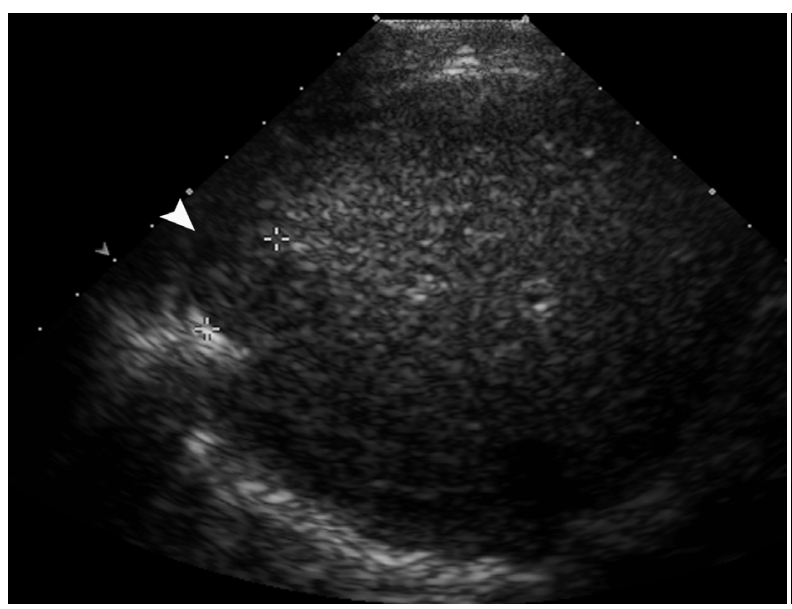

(a)

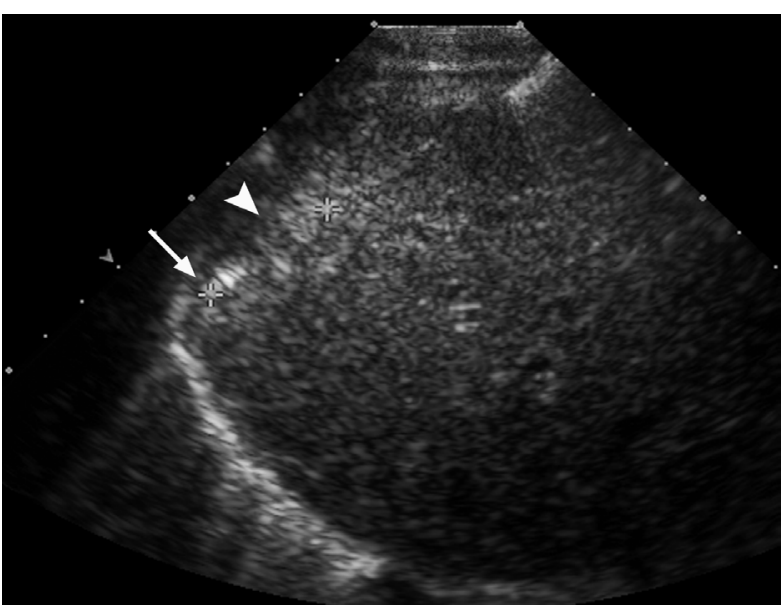

(b)

Figure 1. 80-year-old female with history cirrhosis of unknown etiology with hepatic dome HCC. (a) Longitudinal ultrasound preprocedure image demonstrates the hepatocellular carcinoma lesion with homogeneous hypoechogenicity relative to surrounding parenchyma in the hepatic dome in a peridiaphragmatic location. (b) Longitudinal ultrasound image during the RFA procedure demonstrates single RFA needle extending through the lesion, tip placed approximately 5 mm proximal to the diaphragm. The hepatocellular carcinoma lesion now demonstrates hyperechogencity relative to the surrounding parenchyma, as expected during the ablative process.

nipaque 350, GE Healthcare) was injected at $2.5 \mathrm{ml} / \mathrm{s}$ (Figure 2). Multi-phase MRIs were performed on a General Electric 1.5 Tesla scanner (General Electric, Milwaukee, WI). During and immediately after the procedure, clinical success and complications were determined by the radiologist performing the procedure by physical exam and symptoms.

\subsection{Assessment of Radiofrequency Ablation Zone and Complications}

All the RFA volumes were calculated from CTs obtained at immediate 24 hour follow-up imaging during the portal venous phase using $5 \mathrm{~mm}$ CT slice thickness using the axial, sagittal, and coronal image measurements, and the formula for an ellipsoid of length radius $\times$ width radius $\times$ height radius $\times 0.52$. RFA volume was considered the primary endpoint between the two groups.

We evaluated incidence of complications according to the National Cancer Institute's Common Terminology Criteria for Adverse Events, Version 3.0 [8] with major complications as those that required additional therapy with hospitalization <48 hrs, required major therapy and/or unplanned increased in the level of care, prolonged hospitalization (>48 hrs), or resulted in permanent adverse sequelae or death. All other complications that did not meet this criteria were considered minor, including complications that did not require therapy or required nominal therapy with overnight admission for observation only [8]. These minor complications including pleural effusions were included in our data. We did not measure change in diaphragm thickness as noted by Kang TW [26]. The degree and location of body pain was evaluated, as determined by numeric rating scale of pain, scoring of 0 (no pain) to 10 (greatest degree of pain) during the standard post-ablation hospital observational stay or hospital admission [40]. The maximum score during the hospital stay was evaluated.

We divided the right hepatic lobe/dome into 9 sections (see Figure 3), and assigned the peridiaphragmatic HCC RFA location to one of the 9 sections based on the immediate post-RFA 24-hour follow-up portal venous phase imaging. We evaluated for correlation between the hepatic subsection that contained the lesion undergoing RFA to the patient's pain severity score. We also evaluated for correlation between the hepatic subsection that contained the lesion undergoing RFA to the body area that the patient was experiencing the pain.

\subsection{Assessment of Technical Success and Recurrence}

Determination of technically successful RFA by imaging was defined as a non-enhancing area of low attenuation in the region of the previously noted HCC lesion (see Figure 2).

We evaluated local tumor progression or recurrence on follow-up imaging which included multiphase contrast 


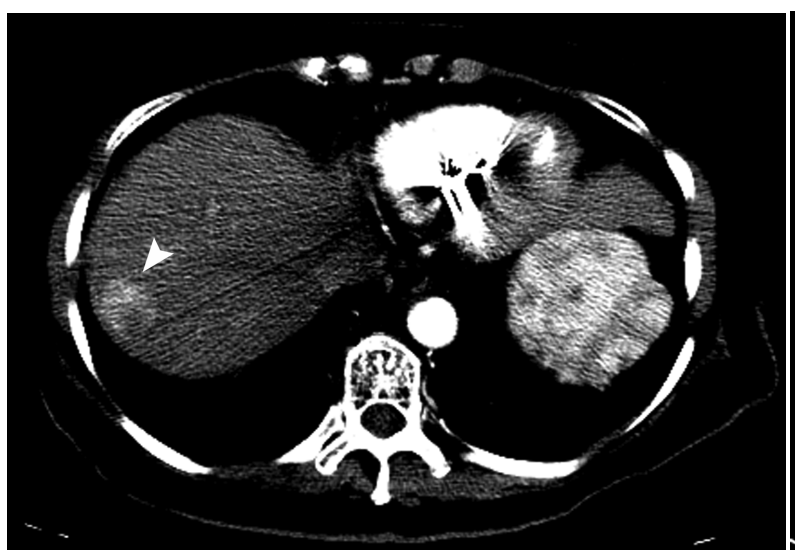

(a)

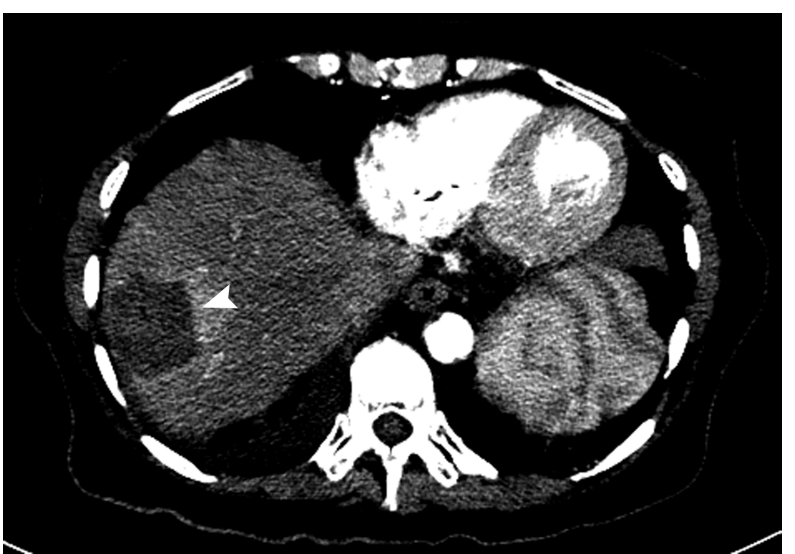

(b)

Figure 2. 80-year-old female with history cirrhosis of unknown etiology who presents for routine screening CT to evaluate for HCC. (a) Axial CT with contrast arterial phase preprocedural image shows right hepatic dome hepatocellular carcinoma lesion directly adjacent to the diaphragm demonstrating early arterial phase enhancement. (b) Axial CT with contrast in arterial phase postprocedure image shows a low attenuation region, which on subsequent phases is non-enhancing, representing ablated region of the previously noted peridiaphragmatic hepatocellular carcinoma. The hyperdense periphery represents surrounding granulation/reactive change and does not enhance.

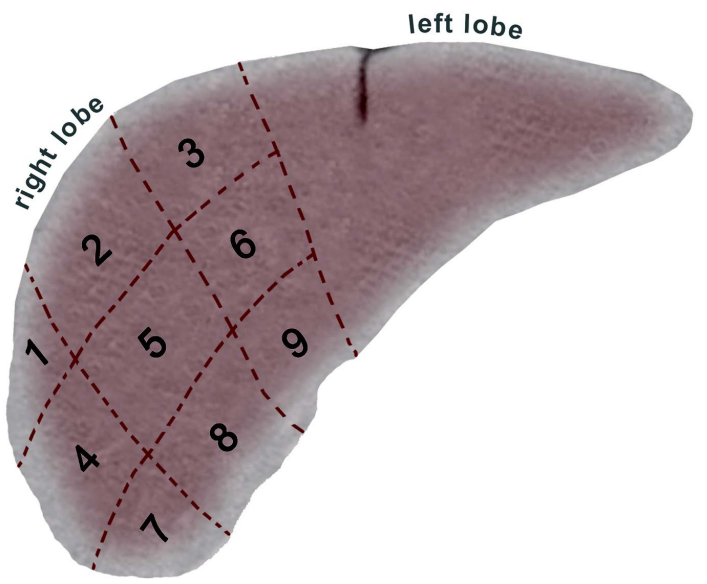

Figure 3. Subdivisions of the right hepatic lobe location used to evaluate for peridiaphragmatic HCCs based on known phrenic nerve main branch location along the medial central right diaphragm and innervation of more peripheral locations of the diaphragm by separate intercostal nerve branches.

enhanced CT and contrast enhanced MRI, which was considered to be the secondary endpoint. Local tumor progression was defined as any nodular enhancement within or abutting the RFA zone that demonstrated HCC characteristics of arterial phase enhancement and washout by delayed phase.

\subsection{Statistical Analysis}

Patient and tumor characteristics of the two groups were compared by using the two-sided Wilcoxon rank-sum test. Fisher's exact test was used to compare the distribution of sex.

RFA volume was compared using the two-sided Wilcoxon rank-sum test. The two-sided Fisher's exact test was used to compare the complete ablation rates volume as well as the major \& minor complications, between the two groups. Complication rate and complete ablation rate were compared between the two groups using the logistic regression in order to adjust for the number of needles. Pain scores were compared between the two groups by the two-sided Wilcoxon rank-sum test. Pain severity score among the diaphragm locations were compared using the Kruskal-Wallis test. Fisher's exact test was used to study the association between the RFA locations and pain locations and also for comparison of distribution of pain location between the two groups. 
Technical success rate comparison was evaluated using the two-sided Fisher's exact test. Time to local recurrence was computed by using the Kaplan-Meier method [41] and the two groups compared by using the log-rank test. Cox proportional hazards $(\mathrm{PH})$ regression [42] was used to compare the time to local tumor recurrence between the peridiaphragmatic HCC and non-peridiaphragmatic HCC groups in order to adjust for the number of needles. All analyses were performed with SAS V9.2 (Cary, NC). A p-value $<0.05$ was considered statistically significant.

\section{Results}

\subsection{Patients}

The 21 patients in the peridiaphragmatic group had liver cirrhosis secondary to Hepatitis $\mathrm{C}(\mathrm{N}=8)$, Hepatitis B $(\mathrm{N}=2)$, ETOH Cirrhosis $(\mathrm{N}=2)$, NASH $(\mathrm{N}=1), \mathrm{ETOH}+\mathrm{HCV}(\mathrm{N}=6), \mathrm{HBV}+\mathrm{HCV}(\mathrm{N}=1)$, other $(\mathrm{N}=$ $1)$. HCC was documented by biopsy $(\mathrm{N}=3)$ or specific $\mathrm{CT}$ criteria $(\mathrm{N}=18)$ of a new arterial enhancing lesion with delayed washout in a setting of cirrhosis. Likewise, similar criteria were used in the nonperidiaphragmatic group defining HCC by Biopsy $(\mathrm{N}=4)$ or by CT criteria $(\mathrm{N}=17)$. In this group cirrhosis was secondary to Hepatitis C $(N=10)$, Hepatitis B $(N=1)$, ETOH cirrhosis $(N=8)$, or other $(N=2)$.

Patient and tumor characteristics of the two patient groups are detailed in Table 1 . The two groups were well matched in age, sex, and MELD score. There was no statistical difference in tumor size between the two groups.

\subsection{Evaluation of Radiofrequency Abalation Zone and Complications}

In the peridiaphragmatic HCC RFA group, the volume of the post RFA zone ranged from 7.4 to $406.5 \mathrm{~cm}^{3}$ (mean $47.9 \pm \mathrm{SD} 83 \mathrm{~cm}^{3}$ ) as determined on immediate followup CT imaging. In the non-peridiaphragmatic HCC RFA group, the volume of the post RFA zone ranged from 6.6 to $91.6 \mathrm{~cm}^{3}$ (mean, $38.1 \pm \mathrm{SD} 27.0 \mathrm{~cm}^{3}$ ). There was no statistical difference between the two groups $(\mathrm{P}=0.962)$.

In the peridiaphragmatic group, 4 of 21 (19.0\%) of patients demonstrated major complications compared to 1/21 (4.7\%) of non-peridiaphragmatic HCC patients (see Table 2). There was no difference in major complications rate $(\mathrm{P}=0.343)$ between the groups. There was no statistically significant difference in the minor complication rate between the two groups $(P=0.061)$. Within the peridiaphragmatic HCC group, 13/21 $(61.9 \%)$ patients demonstrated minor complications, of which pleural effusion was the predominant complication (see Table 3). Within the non-peridiaphragmatic HCC group, six of 21 (28.6\%) patients demonstrated minor complications, of which pleural effusion was the predominant complication (see Table 3).

However, the peridiaphragmatic group that underwent RFA with clustered-needle technique demonstrated a statistically significant higher proportion of major complications with 3/7 (42.9\%) compared to 2/6 (33.3\%) in the non-peridiaphragmatic clustered-needle group $(\mathrm{P}=0.033)$. There was no statistical difference of minor complications between the clustered needle subgroups with $4 / 7$ (57.1\%) demonstrating minor complications in the peridiaphragmatic group compared to 1/6 (16.67\%) of the non-peridiaphragmatic group ( $\mathrm{P}=0.118)$.

Of the 21 patients in the peridiaphragmatic HCC group, 13 had documentation of postprocedure pain. Of the 21 patients in the non-peridiaphragmatic HCC group, 13 had documentation of postprocedure pain (see Table 4). Pain severity between the peridiaphragmatic HCC and non-peridiaphragmatic HCC groups was not significantly different $(\mathrm{P}=0.8802)$. The mean pain score within the peridiaphragmatic HCC group was 6.14 (range 0 - 10), and the mean of non-peridiaphragmatic HCC group 6.29 (range $0-10$ ). There was no statistically significant difference in pain location distribution between the two groups $(\mathrm{P}=0.15)$.

Comparison of pain score differences among the 9 pain locations within the peridiaphragmatic HCC group revealed no statistically significant difference $(\mathrm{P}=0.71)$, detailed in Table 4 .

\subsection{Therapeutic Efficacy and Assessment of Recurrence}

The technical success rate in the peridiaphragmatic HCC group was 19/21 (90.5\%) and 19/21 (90.5\%) in the non-peridiaphragmatic HCC group. There was no statistical difference in technical success rate between the two groups $(\mathrm{P}=1)$. The average age, sex, mean score and tumor site between 21 HCC's located adjacent to and away from the diaphragm.

Local tumor progression was noted in 7/21 (33.3\%) in the peridiaphragmatic HCC group and 8/21 (38.1\%) in 
Table 1. Patient demographics and tumor characteristics.

\begin{tabular}{cccc}
\hline \multirow{2}{*}{ Characteristics } & \multicolumn{2}{c}{ Radiofrequency ablation } & P \\
\cline { 2 - 3 } Age (years) & Peridiaphragmatic $(\mathrm{n}=21)$ & 0.23 \\
Mean \pm SD & $58 \pm 10.5$ & $61 \pm 12.3$ & \\
Range & $43-81$ & $27-81$ & 0.51 \\
Sex (no.) & 16 & 13 & 0.11 \\
Male & 5 & 8 & \\
Female & $12.2 \pm 4.1$ & $10.3 \pm 3.0$ & \\
MELD score & $6.5-20.1$ & $6.4-18.4$ & 0.11 \\
Mean \pm SD & $3.6 \pm 1.5$ & $2.9 \pm 1.2$ & \\
Range & & \\
Tumor size $(\mathrm{cm})$ & & & \\
Mean \pm SD & & & \\
\hline
\end{tabular}

Table 2. Patient major complications.

\begin{tabular}{ccc}
\hline & RFA & \\
\hline & "Patients & Clustered \\
\hline Peridiaphragmatic $^{\text {Pneumonia }}$ & & $2(28.5 \%)$ \\
Pleural effusion $^{*}$ & $2(9.5 \%)$ & \\
Hematoma** $^{* *}$ & $1(4.8 \%)$ & $1(14.3 \%)$ \\
Total $_{\text {Non-peridiaphragmatic }}$ & $1(4.8 \%)$ & $3 / 7(42.8 \%)$ \\
Myocardial ischemia $_{\text {Total }}$ & $4 / 21(19.0 \%)$ & $1(16.7 \%)$ \\
& $1(4.8 \%)$ & $1 / 6(16.7 \%)$ \\
\hline
\end{tabular}

${ }^{*}$ Requiring thoracentesis; ${ }^{* *}$ Requiring transfusion and FFP.

Table 3. Patient minor complications.

\begin{tabular}{ccc}
\hline & RFA & \\
\hline Peridiaphragmatic & "Patients & Clustered \\
\hline Pleural effusion & $8(38.1 \%)$ & $2(28.5 \%)$ \\
Pain & $3(14.2 \%)$ & $2(28.5 \%)$ \\
Fever & $1(4.8 \%)$ & $4 / 7$ \\
Hematoma & $1(4.8 \%)$ & $1(16.7 \%)$ \\
Total & $13 / 21(61.9 \%)$ & $1(16.7 \%)$ \\
Non-peridiaphragmatic & & \\
Pleural effusion & $3(14.2 \%)$ & $2 / 6$ \\
Pain & $1(4.8 \%)$ & $1(4.8 \%)$ \\
Fever & $1(4.8 \%)$ & \\
Ascites & $6 / 21(28.6 \%)$ & \\
Total & & \\
\hline
\end{tabular}

Table 4. Patient pain and location.

\begin{tabular}{ccc}
\hline Location & & RFA \\
\cline { 2 - 3 } & Peridiaphragmatic & Non-peridiaphragmatic \\
\hline Right shoulder & $5(23.8 \%)$ & $1(4.8 \%)$ \\
Right abdomen & $6(28.6 \%)$ & $9(42.9 \%)$ \\
Chest & $1(4.8 \%)$ & 0 \\
Back & 0 & $1(4.8 \%)$ \\
Other & $7(33.3 \%)$ & $7(33.3 \%)$ \\
No pain & $2(9.5 \%)$ & $2(9.5 \%)$ \\
Total with pain data & 13 & 13 \\
\hline
\end{tabular}


the non-peridiaphragmatic HCC group. There was no statistical difference in local tumor progression rates between the two groups $(\mathrm{P}=1)$. The two groups demonstrated no significant difference in time to local tumor recurrence $(\mathrm{P}=0.6707)$. In the non-peridiaphragmatic HCC group, the estimated mean time from RFA procedure to local tumor recurrence is 26.22 months with $\mathrm{SE}+/-6.45$ months, (average follow-up time 12.4 months range 0.1 - 59.1 months). In the peridiaphragmatic HCC group, the estimated mean time to local tumor recurrence is 5.89 months with SE +/- 0.66 months (average follow-up time 9.2 months, range 0.1 - 42.8 months).

\section{Discussion}

Recently the use of artificial ascites prior to radiofrequency ablation therapy of HCC lesions adjacent to the diaphragm has become a more accepted practice and the subject of research. However, review of literature demonstrates only three reported fatalities from RFA of peridiaphragmatic hepatic tumors in instances without the use of hydrodissection [13], [18], [22]. This is an extremely low mortality rate that is comparable to overall hepatic tumor RFA periprocedural reported mortality of $<0.5 \%$ [43]. Also, previous review of literature reports a rate of diaphragmatic injury in only $0.16 \%$ (6/3670) of all hepatic tumor RFA cases [7], [19]. Reports of major complication associated with RFA of peridiaphragmatic HCC lesions demonstrate a wide range from $0 \%-45 \%$ and complications included mostly reports of pneumothoraces and pleural effusions [26], [36], [44]-[46]. We reviewed our results of RF ablation adjacent to the diaphragm.

\subsection{Ablation Zone Volume and Complications}

Our study demonstrates no difference in ablation volume between the two groups. The mean volume of $47.8 \mathrm{~cm}^{3}$ and $38.1 \mathrm{~cm}^{3}$ in the perdiaphragmatic versus non-peridiaphragmatic groups, respectively, is comparable to previous literature [38]. The lack of significant difference in minor complications agrees with Nam et al. [38]. However, they differ from findings of Kang et al. [26] that demonstrated increased minor complications/side effects in RFA of lesions adjacent to the diaphragm, but only statistically significant in the subgroups of right shoulder pain symptoms and transient nonclinical lung injury. In their series only 1/29 patients had severe shoulder pain. In this patient a multi-tine electrode was used. In our prior personal experience we have had trouble visualizing all the tines with an expandable electrode abutting the diaphragm and thus favor an electrode without expandable tines when performing ablations next to the diaphragm.

Our findings, showing no differences in complication rates, favor that artificial ascites may not be necessary. Statistical data showing no difference in major complications between the two groups may have been a result of lower study numbers and decreased statistical power, as the raw data does demonstrate a trend of increased number of minor complications (13 versus 6) within the peridiaphragmatic group comparatively. However, given that the definition criteria for minor complications as those that do not ultimately affect the hospital stay duration or level of care, this trend may not have any clinical significance and should not be a deterrent to ablation of peridiaphragmatic ablations of HCC lesions.

More relevant to clinical practice would be the evaluation of major complication rates between the two groups which we showed no statistical difference. This is in agreement with Kang et al. [26]. Results favor that artificial ascites does not affect post-procedural complications and thus patient morbidity/treatment. Our major complication rate of $19 \%(4 / 21)$ in the peridiaphragmatic group is lower than previous reports that documented rates ranging from $29 \%$ - 45\% [47]-[50]. This discrepancy may be secondary to the differences in technique, of which our operator used gradually ramped-up power [39] and our use of other precautionary measures such as both CT and ultrasonographic confirmation of needle tip position to be $5 \mathrm{~mm}$ from the diaphragm and use of non-expandable electrodes. With proper precaution and technique, lower major complications rates can be obtainable.

Major complications rates were higher with the clustered RFA needle in peridiaphragmatic lesions (3 patients). Also, there was a trend of increased rate of minor complications between the clustered needle peridiaphragmatic compared to non-peridiaphragmatic group (although not reaching statistical significance, $\mathrm{P}=0.118$ ) of $57.1 \%$ versus $16.7 \%$, respectively. This could be because the design of the clustered needle results in greater volume due to the sum of the simultaneous multiprong ablations compared to if each prong were inserted separately [51]. This would more likely injure the adjacent diaphragm as the ablation area is not concentrated more focally and a larger volume is ablated with greater likelihood to involve the diaphragm. Also, the rigid and geometric design of the clustered electrode may be problematic when it is placed adjacent to the diaphragm since not all three electrodes can be placed equidistant from the curved diaphragm. Also the coagulation region of the 
three electrodes beyond the tip may be synergistic so as to potentially involve the diaphragm. It may be prudent to avoid the use of a clustered needle in lesions adjacent to the diaphragm when not using artificial ascites.

\subsection{Pain}

Our study demonstrates no statistically significant difference $(\mathrm{P}=0.148)$ in pain location distribution between the two groups, which disagrees with findings of Kang et al. [26]. However, our raw data of $24 \%$ of peridiaphragmatic RFA patients with right shoulder pain versus 5\% in RFA elsewhere, does demonstrate a trend. Our reported $24 \%$ with right shoulder pain is similar to data from Kang, et al. but is greater than in Head, et al. [7]. This increased rate of shoulder pain in the peridiaphragmatic RFA group could be secondary to inflammation of the diaphragm from RFA, causing associated phrenic nerve irritation.

If one of the purposes of artificial ascites is to avoid pain-related morbidity, a similar number of our patients in the two groups developed pain, and the only difference was in the pain location. This implies that artificial ascites would not ultimately affect pain-related morbidities. However, another important issue to consider is chronicity of pain, which was not evaluated in our study due to its retrospective nature. Investigation of pain chronicity and duration between these two groups in a prospective study could be considered.

We attempted to further evaluate the nature of right shoulder pain in the peridiaphragmatic lesion RFA patient group by subdivision of peridiaphragmatic location (See Figure 3) of the lesion. This is based on known phrenic nerve main branch location along the medial central right diaphragm and innervation of more peripheral locations of the diaphragm by separate intercostal nerve branches [52] (See Figure 4). Our hypothesis was that more central and medially located peridiaphragmatic lesions that underwent RFA would demonstrate more severe pain or be associated with right shoulder pain given proximity to the main right phrenic nerve branches, and that those located more peripherally and laterally with closer proximity to intercostal nerve branches would have less severe pain or not be associated right shoulder pain. Results demonstrate no statistical difference, but our study was very limited by low patient numbers with only 21 peridiaphragmatic lesions patients and only 14 with accessible pain score data. Future studies with greater subject numbers and improved Power for statistical analysis would be useful for evaluation of lesion location and possible association with pain severity and location.

\subsection{Therapeutic Efficacy and Assessment of Recurrence}

Location adjacent to the diaphragm and suggested limitations of decreased visualization of tumors adjacent to

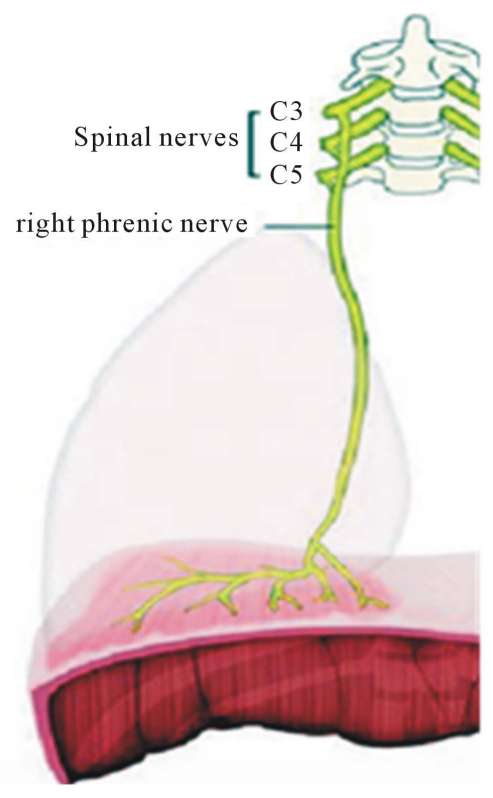

Figure 4. The phrenic nerve anatomy originates from cervical roots C3-C5 and descends inferiorly towards the diaphragm. The right phrenic nerve branches $0.5-1 \mathrm{~cm}$ above the diaphragm before extending into the diaphragmatic muscle. Peripheral diaphragmatic muscles are innervated separate from the phrenic supply, by small filaments from intercostal nerves. 
the diaphragm sonographically did not affect RFA efficacy as our study demonstrates no difference in technical success rate between the two groups. Our technical success rate of $90.5 \%$ showed similar rates compared to other studies with Head, et al. [7] and Livraghi, et al. [3], [17] showing rates of $87.5 \%$ - 90\% in both peridiaphragmatic and non-peridiaphragmatic HCCs.

One of the main proposed purposes of artificial ascites is to improve the sonic window for better visualization of a peri-diaphragmatic tumor, which may increase the technical success rate from improved targeting. With no difference in technical success rates between the two groups, which are also comparable to rates of prior studies as described above, this supports that artificial ascites may not be necessary for better visualization to achieve these rates. This may be because the dual imaging technique using sonography for initial electrode placement guidance with subsequent noncontrast CT confirmation ensures adequate placement and relationship to surrounding structures without the need for artificial ascites. Also, our use of gradual ramp-up of power method with internally cooled electrode may contribute to the efficacy of ablation.

Also, our study demonstrates no significant difference of local tumor recurrence between the two groups, with 7/21 (33.3\%) versus 8/21 (38.1\%) in the peridiaphragmatic HCC and non-peridiaphragmatic groups, respectively. Our recurrence rates are similar to Head, et al. [7], but increased compared to Nam, et al. [38]. But similar to our study, they demonstrated no statistical difference in recurrence rates between the two groups. Our recurrence rates were greater than the $15 \%$ reported by Rhim, et al. [34]; however their study focused solely on lesions less than $3 \mathrm{~cm}$ while our study included lesions that were larger and thus more likely to recur.

Our data favors that RFA of peridiaphragmatic HCC lesions without the use of hydrodissection does not negatively affect outcomes relative to standard random HCC lesions that do not abut the diaphragm. We should note that the survival data shows a mean time to recurrence from RFA procedure in the peridiaphragmatic HCC group of 26.2 months, compared to only 5.9 months in the non-peridiaphragmatic group. However, these numbers can be misleading due to low study numbers and incomplete data for time endpoints in our survival data technique (Kaplan-Meier estimation and log-rank test). A larger study with increased Power would be helpful to further evaluate local recurrence rates between these two groups.

\subsection{Limitations of Study}

This study has several limitations. First, it was a retrospective cohort study. We could not evaluate the true difference between the use of artificial ascites versus lack of its use for lesions adjacent to the diaphragm because we did not perform a prospective randomized controlled study. Second, the small number of our subjects limits our statistical data. Thirdly, some patients were lost to immediate follow-up, limiting our analysis of recurrence ( 3 in the peridiaphragmatic group, and 4 in the nonperidiaphragmatic group). And lastly, our patient pool was taken from a single institution and may not be representative of the population as a whole. In the future, a prospective cohort study with greater power assessing the role of ascites comparing the safety and efficacy of RF ablation using ascites versus no ascites technique for peridiaphragmatic lesions would be useful.

In summary, we performed percutaneous radiofrequency ablation without artificial ascites for HCC in the hepatic dome, which has been considered by some to have higher rate of complications, right shoulder pain, and recurrence. We have shown that the lack of artificial ascites does not increase major complication rate, except with the use of a clustered needle, which we feel should be avoided in peridiaphragmatic cases. In addition, the lack of artificial ascites and ablation location relative to the diaphragm did not correlate to pain severity, although our results were limited by small patient cohort and further evaluation with greater patient numbers would be of benefit. Lastly, we have shown that the diaphragmatic ablation versus non-diaphragmatic location does not increase the rate of recurrence.

\section{References}

[1] Goldberg, S.N., Hahn, P.F., Halpern, E.F., Fogle, R.M. and Gazelle, G.S. (1998) Radio-Frequency Tissue Ablation: Effect of Pharmacologic Modulation of Blood Flow on Coagulation Diameter. Radiology, 209, 761-767.

[2] Goldberg, S.N., Solbiati, L., Hahn, P.F., et al. (1998) Large-Volume Tissue Ablation with Radio Frequency by Using a Clustered, Internally Cooled Electrode Technique: Laboratory and Clinical Experience in Liver Metastases. Radiology, 209, 371-379.

[3] Livraghi, T., Goldberg, S.N., Lazzaroni, S., Meloni, F., Solbiati, L. and Gazelle, G.S. (1999) Small Hepatocellular Carcinoma: Treatment with Radio-Frequency Ablation versus Ethanol Injection. Radiology, 210, 655-661. 
http://dx.doi.org/10.1148/radiology.210.3.r99fe40655

[4] McGahan, J.P. and Dodd III, G.D. (2001) Radiofrequency Ablation of the Liver: Current Status. American Journal of Roentgenology, 176, 3-16. http://dx.doi.org/10.2214/ajr.176.1.1760003

[5] Rhim, H., Goldberg, S.N., Dodd III, G.D., et al. (2001) Essential Techniques for Successful Radio-Frequency Thermal Ablation of Malignant Hepatic Tumors. Radiographics, 21, S17-S35.

http://dx.doi.org/10.1148/radiographics.21.suppl_1.g01oc11s17

[6] Rossi, S., Buscarini, E., Garbagnati, F., et al. (1998) Percutaneous Treatment of Small Hepatic Tumors by an Expandable RF Needle Electrode. American Journal of Roentgenology, 170, 1015-1022. http://dx.doi.org/10.2214/ajr.170.4.9530052

[7] Head, H.W., Dodd III, G.D., Dalrymple, N.C., et al. (2007) Percutaneous Radiofrequency Ablation of Hepatic Tumors against the Diaphragm: Frequency of Diaphragmatic Injury. Radiology, 243, 877-884. http://dx.doi.org/10.1148/radiol.2433060157

[8] Mendiratta-Lala, M., Brook, O.R., Midkiff, B.D., et al. (2010) Quality Initiatives: Strategies for Anticipating and Reducing Complications and Treatment Failures in Hepatic Radiofrequency Ablation. Radiographics, 30, 1107-1122. http://dx.doi.org/10.1148/rg.304095202

[9] de Baere, T., Risse, O., Kuoch, V., et al. (2003) Adverse Events during Radiofrequency Treatment of 582 Hepatic Tumors. American Journal of Roentgenology, 181, 695-700. http://dx.doi.org/10.2214/ajr.181.3.1810695

[10] Dodd III, G.D., Soulen, M.C., Kane, R.A., et al. (2000) Minimally Invasive Treatment of Malignant Hepatic Tumors: At the Threshold of a Major Breakthrough. Radiographics, 20, 9-27. http://dx.doi.org/10.1148/radiographics.20.1.g00ja019

[11] Gillams, A.R. and Lees, W.R. (2000) Radiofrequency Ablation of Liver Tumor 1 Year's Experience with the Lastest Technology [abstr]. European Radiology, 10, D22.

[12] Iannitti, D.A., Dupuy, D.E., Mayo-Smith, W.W. and Murphy, B. (2002) Hepatic Radiofrequency Ablation. Archives of Surgery, 137, 422-426. http://dx.doi.org/10.1001/archsurg.137.4.422

[13] Kim, Y.S., Rhim, H., Sung, J.H., et al. (2005) Bronchobiliary Fistula after Radiofrequency Thermal Ablation of Hepatic Tumor. Journal of Vascular and Interventional Radiology, 16, 407-410. http://dx.doi.org/10.1097/01.RVI.0000150034.77451.6F

[14] Koda, M., Ueki, M., Maeda, N. and Murawaki, Y. (2003) Diaphragmatic Perforation and Hernia after Hepatic Radiofrequency Ablation. American Journal of Roentgenology, 180, 1561-1562. http://dx.doi.org/10.2214/ajr.180.6.1801561

[15] Lim, H.K., Han, S., et al. (2001) Major Complications after Radiofrequency Thermal Ablation of Hepatic Tumors: A Report of the Korean RF Study Group [abstr]. Radiology, 221, 248.

[16] Livraghi, T., Goldberg, S.N., Solbiati, L., Meloni, F., Ierace, T. and Gazelle, G.S. (2001) Percutaneous Radio-Frequency Ablation of Liver Metastases from Breast Cancer: Initial Experience in 24 Patients. Radiology, 220, 145-149. http://dx.doi.org/10.1148/radiology.220.1.r01j101145

[17] Livraghi, T., Melone, F., et al. (2000) Complications after Cool-Tip RF Ablation of Liver Cancer: Initial Report of the Italian Multicenter Cooled-Tip RF Study Group [abstr]. Radiology, 217, 27.

[18] Moumouh, A., Hannequin, J., Chagneau, C., et al. (2005) A Tamponade Leading to Death after Radiofrequency Ablation of Hepatocellular Carcinoma. European Radiology, 15, 234-237. http://dx.doi.org/10.1007/s00330-004-2485-z

[19] Mulier, S., Mulier, P., Ni, Y., et al. (2002) Complications of Radiofrequency Coagulation of Liver Tumours. British Journal of Surgery, 89, 1206-1222. http://dx.doi.org/10.1046/j.1365-2168.2002.02168.X

[20] Raman, S.S., Lu, D.S., Vodopich, D.J., Sayre, J. and Lassman, C. (2000) Creation of Radiofrequency Lesions in a Porcine Model: Correlation with Sonography, CT, and Histopathology. American Journal of Roentgenology, 175, 12531258. http://dx.doi.org/10.2214/ajr.175.5.1751253

[21] Rao, M.P. and Bell, R. (2003) Pulmonary Hemorrhage after Radioablation of Liver Metastases. Anesthesia \& Analgesia, 97, 684-686. http://dx.doi.org/10.1213/01.ANE.0000074126.35091.8A

[22] Wood, T.F., Rose, D.M., Chung, M., Allegra, D.P., Foshag, L.J. and Bilchik, A.J. (2000) Radiofrequency Ablation of 231 Unresectable Hepatic Tumors: Indications, Limitations, and Complications. Annals of Surgical Oncology, 7, 593600.

[23] Kapoor, B.S. and Hunter, D.W. (2003) Injection of Subphrenic Saline during Radiofrequency Ablation to Minimize Diaphragmatic Injury. CardioVascular and Interventional Radiology, 26, 302-304. http://dx.doi.org/10.1007/s00270-003-2704-z

[24] Raman, S.S., Aziz, D., Chang, X., Sayre, J., Lassman, C. and Lu, D. (2004) Minimizing Diaphragmatic Injury during Radiofrequency Ablation: Efficacy of Intraabdominal Carbon Dioxide Insufflation. American Journal of Roentgenology, 183, 197-200. http://dx.doi.org/10.2214/ajr.183.1.1830197 
[25] Raman, S.S., Lu, D.S., Vodopich, D.J., Sayre, J. and Lassman, C. (2002) Minimizing Diaphragmatic Injury during Radio-Frequency Ablation: Efficacy of Subphrenic Peritoneal Saline Injection in a Porcine Model. Radiology, 222, 819823. http://dx.doi.org/10.1148/radiol.2223001805

[26] Kang, T.W., Rhim, H., Kim, E.Y., et al. (2009) Percutaneous Radiofrequency Ablation for the Hepatocellular Carcinoma Abutting the Diaphragm: Assessment of Safety and Therapeutic Efficacy. Korean Journal of Radiology, 10, 34-42. http://dx.doi.org/10.3348/kjr.2009.10.1.34

[27] Kim, Y.S., Rhim, H. and Paik, S.S. (2006) Radiofrequency Ablation of the Liver in a Rabbit Model: Creation of Artificial Ascites to Minimize Collateral Thermal Injury to the Diaphragm and Stomach. Journal of Vascular and Interventional Radiology, 17, 541-547. http://dx.doi.org/10.1097/01.RVI.0000208305.65202.84

[28] Lee, S., Rhim, H., Kim, Y.S., et al. (2009) Percutaneous Radiofrequency Ablation of Hepatocellular Carcinomas: Factors Related to Intraprocedural and Postprocedural Pain. American Journal of Roentgenology, 192, 1064-1070. http://dx.doi.org/10.2214/AJR.08.1350

[29] Rhim, H. (2005) Complications of Radiofrequency Ablation in Hepatocellular Carcinoma. Abdom Imaging, 30. 409418. http://dx.doi.org/10.1007/s00261-004-0255-7

[30] Rhim, H., Dodd III, G.D., Chintapalli, K.N., et al. (2004) Radiofrequency Thermal Ablation of Abdominal Tumors: Lessons Learned from Complications. Radiographics, 24, 41-52. http://dx.doi.org/10.1148/rg.241025144

[31] Kondo, Y., Yoshida, H., Shiina, S., Tateishi, R., Teratani, T. and Omata, M. (2006) Artificial Ascites Technique for Percutaneous Radiofrequency Ablation of Liver Cancer Adjacent to the Gastrointestinal Tract. British Journal of Surgery, 93, 1277-1282. http://dx.doi.org/10.1002/bjs.5374

[32] Chen, M.H., Yang, W., Yan, K., et al. (2008) Radiofrequency Ablation of Problematically Located Hepatocellular Carcinoma: Tailored Approach. Abdom Imaging, 33, 428-436. http://dx.doi.org/10.1007/s00261-007-9283-4

[33] Rhim, H. and Lim, H.K. (2009) Radiofrequency Ablation for Hepatocellular Carcinoma Abutting the Diaphragm: The Value of Artificial Ascites. Abdom Imaging, 34, 371-380. http://dx.doi.org/10.1007/s00261-008-9408-4

[34] Rhim, H., Lim, H.K., Kim, Y.S. and Choi, D. (2008) Percutaneous Radiofrequency Ablation with Artificial Ascites for Hepatocellular Carcinoma in the Hepatic Dome: Initial Experience. American Journal of Roentgenology, 190, 91-98. http://dx.doi.org/10.2214/AJR.07.2384

[35] Lee, E.J., Rhim, H., Lim, H.K., Choi, D., Lee, W.J. and Min, K.S. (2008) Effect of Artificial Ascites on Thermal Injury to the Diaphragm and Stomach in Radiofrequency Ablation of the Liver: Experimental Study with a Porcine Model. American Journal of Roentgenology, 190, 1659-1664. http://dx.doi.org/10.2214/AJR.07.2993

[36] Song, I., Rhim, H., Lim, H.K., Kim, Y.S. and Choi, D. (2009) Percutaneous Radiofrequency Ablation of Hepatocellular Carcinoma Abutting the Diaphragm and Gastrointestinal Tracts with the Use of Artificial Ascites: Safety and Technical Efficacy in 143 Patients. European Radiology, 19, 2630-2640. http://dx.doi.org/10.1007/s00330-009-1463-x

[37] Perrault, J., McGill, D.B., Ott, B.J. and Taylor, W.F. (1978) Liver Biopsy: Complications in 1000 Inpatients and Outpatients. Gastroenterology, 74, 103-106.

[38] Nam, S.Y., Rhim, H., Kang, T.W., et al. (2010) Percutaneous Radiofrequency Ablation for Hepatic Tumors Abutting the Diaphragm: Clinical Assessment of the Heat-Sink Effect of Artificial Ascites. American Journal of Roentgenology, 194, W227-W231. http://dx.doi.org/10.2214/AJR.09.2979

[39] McGahan, J.P., Loh, S., Boschini, F.J., et al. (2010) Maximizing Parameters for Tissue Ablation by Using an Internally Cooled Electrode. Radiology, 256, 397-405. http://dx.doi.org/10.1148/radiol.09090662

[40] McCaffery, M. and Beebe, A. (1993) Pain: Clinical Manual for Nursing Practice. V.V. Mosby Company, Baltimore.

[41] Kaplan, E.L. and Meier, P. (1958) Nonparametric Estimation fro Incomplete Observations. Journal of the American Statistical Association, 53, 457-448. http://dx.doi.org/10.1080/01621459.1958.10501452

[42] Cox, D.D.R. (1972) Regression Models and Life-Tables. Journal of the Royal Statistical Society, Series B (Methodological), 34, 187-220.

[43] Curley, S.A., Marra, P., Beaty, K., et al. (2004) Early and Late Complications after Radiofrequency Ablation of Malignant Liver Tumors in 608 Patients. Annals of Surgery, 239, 450-458. http://dx.doi.org/10.1097/01.sla.0000118373.31781.f2

[44] de Baere, T., Dromain, C., Lapeyre, M., et al. (2005) Artificially Induced Pneumothorax for Percutaneous Transthoracic Radiofrequency Ablation of Tumors in the Hepatic Dome: Initial Experience. Radiology, 236, 666-670. http://dx.doi.org/10.1148/radiol.2362040992

[45] Shibata, T., Maetani, Y., Kubo, T., Itoh, K., Togashi, K. and Hiraoka, M. (2004) Transthoracic Percutaneous Radiofrequency Ablation for Liver Tumors in the Hepatic Dome. Journal of Vascular and Interventional Radiology, 15, 1323-1327. http://dx.doi.org/10.1097/01.RVI.0000132297.97113.C4

[46] Toyoda, M., Kakizaki, S., Horiuchi, K., et al. (2006) Computed Tomography-Guided Transpulmonary Radiofrequency 
Ablation for Hepatocellular Carcinoma Located in Hepatic Dome. World Journal of Gastroenterology, 12, 608-611.

[47] Goldberg, S.N., Hahn, P.F., Tanabe, K.K., et al. (1998) Percutaneous Radiofrequency Tissue Ablation: Does Perfusion-Mediated Tissue Cooling Limit Coagulation Necrosis? Journal of Vascular and Interventional Radiology, 9, 101111. http://dx.doi.org/10.1016/S1051-0443(98)70491-9

[48] Lu, D.S., Raman, S.S., Vodopich, D.J., Wang, M., Sayre, J. and Lassman, C. (2002) Effect of Vessel Size on Creation of Hepatic Radiofrequency Lesions in Pigs: Assessment of the "Heat Sink” Effect. American Journal of Roentgenology, 178, 47-51. http://dx.doi.org/10.2214/ajr.178.1.1780047

[49] Hayes, D.L., Charboneau, J.W., Lewis, B.D., Asirvatham, S.J., Dupuy, D.E. and Lexvold, N.Y. (2001) Radiofrequency Treatment of Hepatic Neoplasms in Patients with Permanent Pacemakers. Mayo Clinic Proceedings, 76, 950-952.

[50] Llovet, J.M., Vilana, R., Bru, C., et al. (2001) Increased Risk of Tumor Seeding after Percutaneous Radiofrequency Ablation for Single Hepatocellular Carcinoma. Hepatology, 33, 1124-1129. http://dx.doi.org/10.1053/jhep.2001.24233

[51] de Baere, T., Denys, A., Wood, B.J., et al. (2001) Radiofrequency Liver Ablation: Experimental Comparative Study of Water-Cooled versus Expandable Systems. American Journal of Roentgenology, 176, 187-192. http://dx.doi.org/10.2214/ajr.176.1.1760187

[52] Muller Botha, G.S. (1957) The Anatomy of Phrenic Nerve Termination and the Motor Innervation of the Diaphragm. Thorax, 12, 50-56. http://dx.doi.org/10.1136/thx.12.1.50 